\title{
Characterization of Adult Canine Kidney Epithelial Stem Cells That Give Rise to Dome-Forming Tubular Cells
}

\author{
Te-Chuan Chen, ${ }^{1}$ Manish Neupane, ${ }^{2}$ Shao-Ju Chien, ${ }^{3}$ Feng-Rong Chuang, ${ }^{1}$ Robert B. Crawford, ${ }^{4}$ \\ Norbert E. Kaminski, ${ }^{4}$ and Chia-Cheng Chang $^{5}$
}

Dome formation can occur in cultured tubular epithelial cells originating from various tissues, including the mammary gland and the kidney. The isolation and characterization of normal kidney epithelial stem cells that give rise to dome-forming tubular cells have never been reported. We attempted to isolate and characterize canine kidney epithelial stem cells using a simple cell culture method that we have previously used to isolate other adult human stem cells. Dome-forming kidney epithelial cells were derived from dissociated adult canine kidney tissues that were cultured in a modified keratinocyte serum-free medium supplemented with $N$-acetyl-Lcysteine, L-ascorbic acid 2-phosphate, nicotinamide, and fetal bovine serum. These cells exhibited high selfrenewal capacity in long-term culture (growth for $>13$ months and 30 cumulative population doublings) and exhibited characteristics of stem cells, including (1) deficiency in gap junctional intercellular communication, (2) anchorage-independent growth, (3) expression of stem cell markers octamer-binding transcription factor 4 and SRY (sex determining region Y)-box 2, (4) expression of cell surface markers CD24 and CD133, and (5) multipotent differentiation into osteoblasts, adipocytes, chondrocytes, and dome-forming tubular cells. Most of these characteristics are shared by the well-known canine renal tubule-derived immortalized Madin-Darby Canine Kidney cell line. Furthermore, the putative canine kidney stem cells developed in this study formed budding tubule-like organoids on Matrigel and required high cell density $\left(>4,000 \mathrm{cells} / \mathrm{cm}^{2}\right)$ for sustained growth and confluency for dome formation. The signal transducer and activator of transcription-3 (STAT3) phosphorylation inhibitor, AG490, inhibited colony-forming efficiency and dome formation, whereas lipopolysaccharide, an activator of STAT3, increased colony-forming efficiency in a dose-dependent manner. These results are consistent with the hypothesis that high cell density induces STAT3 expression, which promotes both stem cell self-renewal and differentiation into tubular cells. Our novel cell culture method should be useful for the future development of normal human kidney stem cells for clinical applications and for studying mechanisms of nephrotoxicity.

Keywords: kidney multipotent stem cells, dome-forming tubular cells, STAT3

\section{Introduction}

$\mathrm{T}^{\mathrm{s}}$ HE INCIDENCE AND PREVALENCE of end-stage renal disease (ESRD) are increasing globally [1,2]. Patients with ESRD have been treated by renal replacement therapies including peritoneal dialysis, hemodialysis, and kidney transplantation. These treatments, however, have inherent shortcomings, including comorbidities, poor quality of life, and a shortage of organ donors.

Stem cells are undifferentiated cells with the capacity for unlimited or prolonged self-renewal, and the remarkable potential to give rise to many different cell types in the body. Therefore, stem cells show great potential in regenerative and reparative medicine for the treatment of diseases that are not conventionally curable. There are three major types of stem cells. Embryonic stem (ES) cells might provide an unlimited supply of stem cells due to their infinite lifespan and high differentiation potential. However, drawbacks of ES cells include the potential for teratoma development besides ethical concern. Induced pluripotent stem cells (iPSCs) can be derived after ectopic expression of transcription factors in many different animal and human

\footnotetext{
${ }^{1}$ Division of Nephrology, Department of Internal Medicine, and ${ }^{3}$ Division of Cardiology, Department of Pediatrics, Kaohsiung Chang Gung Memorial Hospital, Chang Gung University College of Medicine, Kaohsiung, Taiwan.

${ }^{2}$ Department of Medical Oncology, Thomas Jefferson University, Philadelphia, Pennsylvania.

${ }^{4}$ Institute for Integrative Toxicology and ${ }^{5}$ Department of Pediatrics and Human Development, Michigan State University, East Lansing, Michigan.
} 
cell types. Although there are no ethical concerns associated with the development of iPSCs, potential drawbacks of using these cells include mutations, dysplasia, or hyperplasia due to multiple retroviral chromosomal integrations, or aberrant expression of transcription factors [3]. Adult stem cells can be derived from various adult tissues using suitable cell culture media and conditions, without the need for ectopic expression of transcription factors. These adult stem cells may have limited proliferative capacity and differentiation potential compared with ES cells and iPSCs. However, adult stem cells are safer for clinical use and are by far the most common type of stem cell used in clinical trials (34, 52, and 573 clinical trials have used ES cells, iPSCs, and adult stem cells, respectively, as of July 30, 2019; http:// clinicaltrials.gov).

We previously reported the development of various animal and human adult stem cells from a range of sources (ie, mammary [4,5], adipose tissue [6,7], gastric [8], liver [9], and amniotic fluid [10]). Successful development of these cells was mainly ascribed to the use of a medium containing $\mathrm{N}$-acetyl-L-cysteine (NAC) and L-ascorbic acid 2-phosphate (Asc-2P), which alters the cellular redox state and facilitates the expression of major stem cell transcription factors. In this study, we attempted to isolate stem cells from the adult canine kidney using a similar technique, and found that it is possible to isolate dome-forming canine kidney epithelial cells with stem cell characteristics similar to those exhibited by the canine renal tube-derived Madin-Darby Canine Kidney (MDCK) cell line [11,12]. These canine kidney epithelial cells expressed kidney stem/progenitor cell surface markers, CD24 and CD133, pluripotency-associated stem cell markers, octamer-binding transcription factor 4 (OCT4), and SRY (sex determining region Y)-box 2 (SOX2 ), and were capable of extended self-renewal as well as multilineage differentiation. Furthermore, we found that high cell density was required for both sustained growth and dome formation by these cells. Since it was previously shown that MDCK cells at confluency activate signal transducer and activator of transcription-3 (STAT3) and trigger dome formation [13], we hypothesize that high cell density induces STAT3 expression that promotes both selfrenewal and differentiation into tubular cells.

\section{Materials and Methods}

\section{Cell culture medium}

The medium used to develop putative canine kidney epithelial stem/progenitor cell cultures is a modified MCDB 153 medium (Keratinocyte-SFM; Gibco) supplemented with $2 \mathrm{mM}$ NAC (catalog no. A8199; Sigma) and $0.2 \mathrm{mM}$ Asc-2P (catalog no. A8960; Sigma) (referred to as K-NAC medium) [6]. The calcium concentration of this medium is $0.09 \mathrm{mM}$. The growth factors/hormones added to this medium include recombinant epithelial growth factor $(5 \mathrm{ng} / \mathrm{mL})$, bovine pituitary extract $(50 \mu \mathrm{g} / \mathrm{mL})$, insulin $(5 \mu \mathrm{g} / \mathrm{mL})$, hydrocortisone $(74 \mathrm{ng} / \mathrm{mL})$, and 3,3',5-triiodo-DL-thyronine $\left(\mathrm{T}_{3}\right)$ $(6.7 \mathrm{ng} / \mathrm{mL})$. NAC, a potent antioxidant, has been shown to promote the self-renewal of precursor cells [14] and is readily deacetylated intracellularly to yield L-cysteine, thereby enhancing the production of glutathione [15]. Asc$2 \mathrm{P}$ is a stable precursor that provides ascorbic acid in cell culture [16,17]. Ascorbate can be antioxidative or pro- oxidative (due to reversible conversion between ascorbate and dehydroascorbate) depending on its concentration and the concentration of metal ions [18]. The K-NAC medium is also supplemented with nicotinamide $(5 \mathrm{mM})$, which is a poly (adenosine diphosphate-ribose) polymerase inhibitor that regulates sirtuins and the expression of genes related to cell survival and longevity $[19,20]$. In kidney cell differentiation experiments, a modified Eagle's minimal essential medium (D-medium) [21] was used.

\section{Isolation of dome-forming canine kidney epithelial cells}

A whole canine kidney was excised shortly after euthanasia, which was carried out for reasons unrelated to this study. The kidney was washed with phosphate-buffered saline (PBS), and then the outer fascia and fibrotic tissue were removed and minced into small pieces in a $60 \mathrm{~mm}$ plate using scalpels. After washing the minced tissue with PBS to remove the majority of erythrocytes, small pieces were seeded into $60 \mathrm{~mm}$ plates and incubated with serum-free K-NAC medium supplemented with $0.1 \%$ penicillin-streptomycin (catalog no. 15140-122; Gibco). To facilitate the attachment of suspended cells and tissues to the plate, minimal initial volumes of medium were used. Medium was renewed daily, and cell colonies were developed from pieces of tissue after 7-10 days (Fig. 1a). These colonies were isolated using the glass ring/trypsin method, and were transferred into wells of 12-well plates and incubated with K-NAC medium supplemented with $10 \%$ fetal bovine serum (FBS) and $5 \mathrm{mM}$ nicotinamide. These cells continued to grow until confluency and exhibited contact-insensitive growth and dome formation (Fig. 1b). Some cells would detach and float in the medium; these floating cells could be repeatedly transferred to $100 \mathrm{~mm}$ plates to give rise to a large number of cells. This procedure was found to be more efficient than trypsinization, which tended to induce cell differentiation. Dome-forming colonies in $100 \mathrm{~mm}$ plates could be enriched and purified by removing undesired nondome-forming colonies by scraping with a rubber policeman. Every other day, half of the cell culture medium in plate (conditioned medium) was replaced with fresh medium. Cells in $100 \mathrm{~mm}$ plates could then be trypsinized and transferred to T-75 flasks to increase number of cells. All cell cultures were incubated at $37^{\circ} \mathrm{C}$ in incubators supplied with humidified air and $5 \% \mathrm{CO}_{2}$.

\section{Cumulative population doubling levels}

The cumulative population doubling level (cpdl) was calculated to determine the proliferation capacity of cells using the equation: $\ln \left(N_{\mathrm{f}} / N_{\mathrm{i}}\right) / \ln 2$, where $N_{\mathrm{i}}$ and $N_{\mathrm{f}}$ are initial and final number of cells, respectively, and $\ln 2$ is the natural $\log$. The initial number of cells was $2 \times 10^{5}$ cells in a $100 \mathrm{~mm}$ dish for each propagation. To obtain the final cpdl, cpdl in continuous subculture periods was added.

\section{Anchorage-independent growth assay}

To determine anchorage-independent growth (AIG), agarose (0.5\%, Type I; Sigma) was prepared in K-NAC medium containing 5\% FBS at $39^{\circ} \mathrm{C}$, and was added to $60 \mathrm{~mm}$ dishes and allowed to solidify in a $37^{\circ} \mathrm{C}$ incubator. A total of 50,000 cells suspended in medium containing $0.33 \%$ agarose were 
FIG. 1. Primary canine kidney epithelial cell cultures were successfully established from canine kidney tissue. Initial cell growth from minced canine kidney tissue is shown (a). Colonies with epithelial morphology were developed in a week. Confluent cell culture with dome-forming colonies exhibited contact-insensitive growth. Repeated transfer of the detached floating cells from the cell culture was able to give rise to cell colonies and a large number of cells (b). Domes were distinct from adherent primitive cells and showed three-dimensional structures $(\mathbf{c}, \mathbf{d})$. Images (c, d) were acquired at different focal planes. Scale bars: (a, b) $100 \mu \mathrm{m}$; (c, d) $50 \mu \mathrm{m}$.
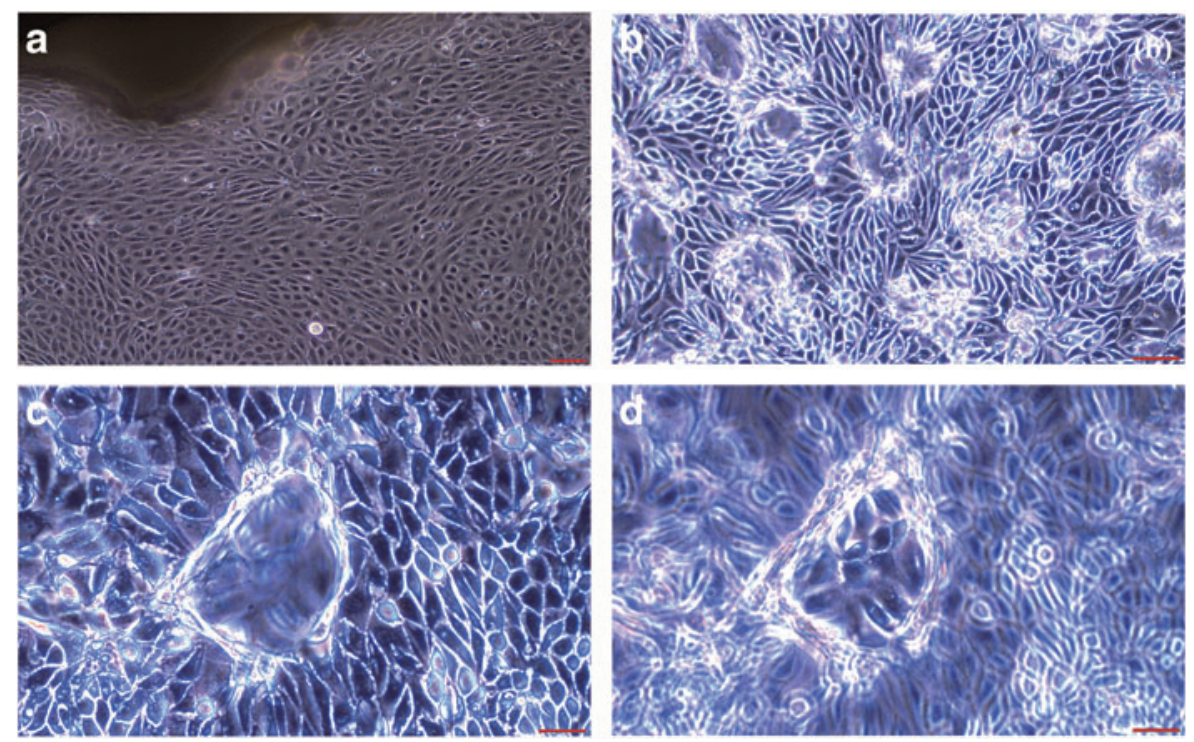

overlaid on top of the solidified $0.5 \%$ agarose layer. The plates were incubated at $37^{\circ} \mathrm{C}$, and $\mathrm{K}-\mathrm{NAC}$ medium containing $5 \mathrm{mM}$ nicotinamide and $10 \%$ FBS was added 3 days after cell inoculation and renewed every 3 days. After 4 weeks, colonies were stained and scored using a microscope.

\section{Gap junctional intercellular communication}

Gap junctional intercellular communication (GJIC) was studied by the scrape loading/dye transfer technique reported previously [22]. In brief, this technique involves (1) the growth of a confluent cell culture in $35 \mathrm{~mm}$ plates over a period of 1-2 days; (2) the addition of $2 \mathrm{~mL}$ Lucifer Yellow (catalog no. L0259, $0.5 \mathrm{mg} / \mathrm{mL}$ in PBS; Sigma); (3) scraping of the cell monolayer with a surgical blade to allow entry of the dye into damaged cells, which transfer the dye to neighboring cells within $3 \mathrm{~min}$ if the cells are GJIC competent; and (4) removal of the dye solution and washing of the cell monolayer with PBS. Dye transfer between cells was visualized with a Nikon Eclipse TE300 UV fluorescence microscope and recorded using a digital camera connected to a computer.

\section{Flow cytometry}

Subconfluent canine kidney epithelial cells (clone DK-701) were grown as described previously in $60 \mathrm{~mm}$ dishes and dissociated from the dishes using a nonenzymatic dissociation solution (Cellstripper; Corning). Fluorescence-activated cell sorting (FACS) buffer (Hank's balanced salt solution, 1\% bovine serum albumin, $0.1 \% \mathrm{NaN}_{3}$ ) was used to wash cells between staining and fixing steps. Cells were incubated with FACS buffer containing 20\% fetal calf serum and antimouse CD16/CD32 (BD Biosciences) to help block Fc receptors, if present. Cells were then incubated with antibodies CD24 (clone M1/69; Biolegend) and CD133 (clone 13A4; eBiosciences) and washed three times with FACS buffer. BD Cytofix $^{\mathrm{TM}}$ (BD Biosciences) was used to fix cells per the manufacturer's protocol. Cells were analyzed on an FACS BD Canto II $^{\mathrm{TM}}$ (BD Biosciences). After acquisition, data analysis was performed using FLOWJO v10 software.

\section{Reverse transcription polymerase chain reaction}

Total RNA was extracted from cells using a Versagene RNA purification kit (Gentra) and treated with DNase I to remove contaminating DNA. cDNA was synthesized from $1 \mu \mathrm{g}$ total RNA using random hexamer primers and Superscript III reverse transcriptase (Invitrogen). For amplification of cDNA, we used primers specific for OCT4, SOX-2, and NANOG (stem cell transcription factors) that were derived from coding regions of the corresponding genes [7]. A total of $25 \mu \mathrm{L}$ polymerase chain reaction (PCRs) were prepared with $2 \mu \mathrm{L}$ cDNA, 5 pmol of each primer, $0.5 \mathrm{U}$ of Taq polymerase (Invitrogen), and final concentrations of $40 \mu \mathrm{M}$ deoxyribonucleotide triphosphate, $2 \mathrm{mM} \mathrm{MgCl}_{2}, 20 \mathrm{mM}$ Tris- $\mathrm{HCl}$, and $50 \mathrm{mM} \mathrm{KCl}$. Cycling conditions were as follows: $94^{\circ} \mathrm{C}$ for $4 \mathrm{~min} ; 30-35$ cycles at $94^{\circ} \mathrm{C}$ for $1 \mathrm{~min}$, annealing for $1 \mathrm{~min}$, and $72^{\circ} \mathrm{C}$ for $1 \mathrm{~min}$; followed by $72^{\circ} \mathrm{C}$ for $5 \mathrm{~min}$. PCR products were separated on $2 \%$ agarose gels by electrophoresis, stained with ethidium bromide, and visualized under UV light. The digital images were captured using AlphaImager software. PCR products were gel purified using a Qiaex II Gel Extraction Kit (Qiagen), sequenced with an automated sequencer, and verified by alignment to the canine genome.

\section{Multipotent differentiation}

Adipogenesis. A total of $4 \times 10^{5}$ cells were plated in $35 \mathrm{~mm}$ dishes and treated with rosiglitazone $(5 \mu \mathrm{M})$, 3isobutyl-1-methylxanthine (IBMX; $500 \mu \mathrm{M})$, dexamethasone $(1 \mu \mathrm{M})$, indomethacin $(100 \mu \mathrm{M})$, insulin $(10 \mu \mathrm{g} / \mathrm{mL})$, glucose $(4.5 \mathrm{~g} / \mathrm{L})$, and $5 \%$ rabbit serum for 21 days. The induction medium with supplementations was renewed every 3 days. Oil red $\mathrm{O}$ staining was performed to reveal lipid droplet formation.

Osteogenesis. A total of $4 \times 10^{5}$ cells were plated in $35 \mathrm{~mm}$ dishes and treated with dexamethasone $(0.1 \mu \mathrm{M})$, Asc$2 \mathrm{P}(50 \mu \mathrm{M})$, and $\beta$-glycerophosphate disodium (10 mM; DAG cocktail) in D-medium containing $10 \%$ FBS for $6-8$ weeks, with medium change every 3 days. Alizarin red staining was carried out to detect calcified extracellular matrix deposit. 
Chondrogenesis. Micromass cultures of cells $\left(1 \times 10^{5}\right.$ cells $/ 10 \mu \mathrm{L}$ ) were allowed to form in 24-well plates for $2.5 \mathrm{~h}$ before treatment with transforming growth factor- $\beta 1(10 \mathrm{ng} /$ $\mathrm{mL}$ ), Asc-2P $(50 \mu \mathrm{M})$, and insulin $(6.25 \mu \mathrm{g} / \mathrm{mL}$ ) (TAI cocktail) for 14 days, with medium change every 3 days. The micromass was stained with Alcian blue for the presence of sulfated proteoglycan-rich matrix.

\section{Three-dimensional growth on Matrigel}

Liquid Matrigel was added to $35 \mathrm{~mm}$ dishes $(0.5 \mathrm{~mL} /$ plate) and allowed to solidify in an incubator at $37^{\circ} \mathrm{C}$. A total of $1 \times 10^{7}$ cells in $0.5 \mathrm{~mL}$ K-NAC medium containing $10 \%$ FBS and $5 \mathrm{mM}$ nicotinamide were then added onto the Matrigel for three-dimensional cell growth.

\section{Regulation of self-renewal and dome-forming tubular differentiation of canine stem/progenitor cells by STAT3}

For this study, $4 \times 10^{4}$ cells were plated in $35 \mathrm{~mm}$ dishes for 1 day and then treated with AG490 (2.5, 5, or $10 \mu \mathrm{M}$ and dimethyl sulfoxide [DMSO] as vehicle control) or lipopolysaccharide (LPS) $(0.1,0.2$, or $0.4 \mu \mathrm{g} / \mathrm{mL})$. The medium was renewed once every 3 days. Both dome-forming and nondome-forming colonies were counted after 4 weeks.

\section{Statistical analysis}

Mean \pm SD data were analyzed using one-way analysis of variance followed by post hoc Dunnett's multiple comparison test (GraphPad Prism).

\section{Results}

\section{Canine kidney epithelial cell cultures were successfully established from canine kidney tissues}

Canine kidney cell colonies were initially derived from minced kidney tissues. We used the serum-free K-NAC medium [6] to develop cell populations with characteristics of stem cells. The use of this cell culture medium and the methods described previously yielded colonies displaying epithelial cell morphology after 7-19 days, as shown in Fig. 1a. These colonies were isolated by glass ring/trypsin method and propagated for further characterization.

\section{Canine kidney epithelial cells that were capable of forming dome-like structures can be continuously derived from single cells of the initial dome-forming cell culture}

Although canine kidney cell colonies were initially derived in serum-free K-NAC medium [6], we observed that these cells grew more efficiently in K-NAC medium supplemented with $5 \mathrm{mM}$ nicotinamide and $10 \%$ FBS. We, therefore, used this serum-containing medium to determine the cells' proliferation potential and colony-forming capacity on plastic or soft agar.

The isolated kidney epithelial cell colonies proliferated in wells and displayed contact-insensitive growth (Fig. 1b). Dome-like structures appeared in confluent cell cultures (Fig. 1c, d), similar to those reported for the canine MDCK cell line [11]. These cells showed density-dependent growth after subculture, that is, optimum cell proliferation density $>4,000 /$ $\mathrm{cm}^{2}$. Furthermore, confluent dome-forming canine kidney epithelial cell cultures in 12-well plates could be maintained $>13$ months with medium change. Floating cells that detached from these adherent cultures could also be repeatedly transferred to new wells or plates to initiate new dome-forming cultures.

\section{Canine kidney epithelial cells express stem cell markers on the cell surface}

To examine whether the population of canine kidney epithelial cells express the well-known cell surface markers for renal stem/progenitor cells (see references in "Discussion" section), we performed flow cytometry to analyze the expression of CD24 and CD133 on the surface of normal canine cells (clone DK-701). We found that $22.2 \%$ of the cells express CD24 on the surface (Fig. 2a, c) and 5.13\% of the cells expressed CD133 on their surface (Fig. 2b, c). In addition, double positive cells expressing both CD24 and CD133 were present at $2.66 \%$ (Fig. 2c).

\section{Canine kidney epithelial cells express pluripotency- associated transcription factors}

Experiments were carried out to detect the expression of important stem cell markers by reverse transcription PCR. Both the canine kidney epithelial cells developed in this study, and MDCK cells, expressed OCT4 and SOX-2 as shown by the expression of mRNA encoding OCT4 in Fig. 2d (274 bp product) and SOX-2 in Fig. 2e (142 bp product) in normal canine kidney (NCK) cells and MDCK cells. However, NANOG expression was not detected in these cells (data not shown).

\section{Canine kidney epithelial cells proliferate in culture for finite time and display AIG in soft agar}

The proliferation potential of dome-forming canine kidney epithelial cells was determined by estimating their cpdl in continuous culture. We found that these cells had a finite lifespan, with $\sim 30$ population doublings in a period of 42 days. These cells were also capable of colony formation in soft agar (ie, AIG) (Fig. 3a). The frequency of AIG was found to be $\sim 4 \%$ (Fig. 3a) compared with an AIG frequency of $\sim 8 \%$ for MDCK cells (Fig. 3b).

\section{Canine kidney epithelial cells are deficient in GJIC}

The lack of GJIC is a common property of stem cells and cancer cells [23]. Therefore, we carried out experiments to determine whether the canine kidney epithelial cells developed in this study, and immortalized canine MDCK cells, were capable of GJIC. Experiments using the scrape-loading dye transfer technique [22] revealed that both of these cell types are GJIC deficient as shown in Fig. $3 \mathrm{c}$ and $\mathrm{d}$ for normal canine epithelial cells and in Fig. $3 \mathrm{e}$ and $\mathrm{f}$ for MDCK cells. As shown, the dye retained in the damaged cells without transferring to neighboring cells as shown by GJIC-deficient cells [22].

\section{Canine kidney epithelial cells are capable of multilineage differentiation}

We have previously reported reliable protocols for osteogenic, adipogenic, and chondrogenic differentiation for 


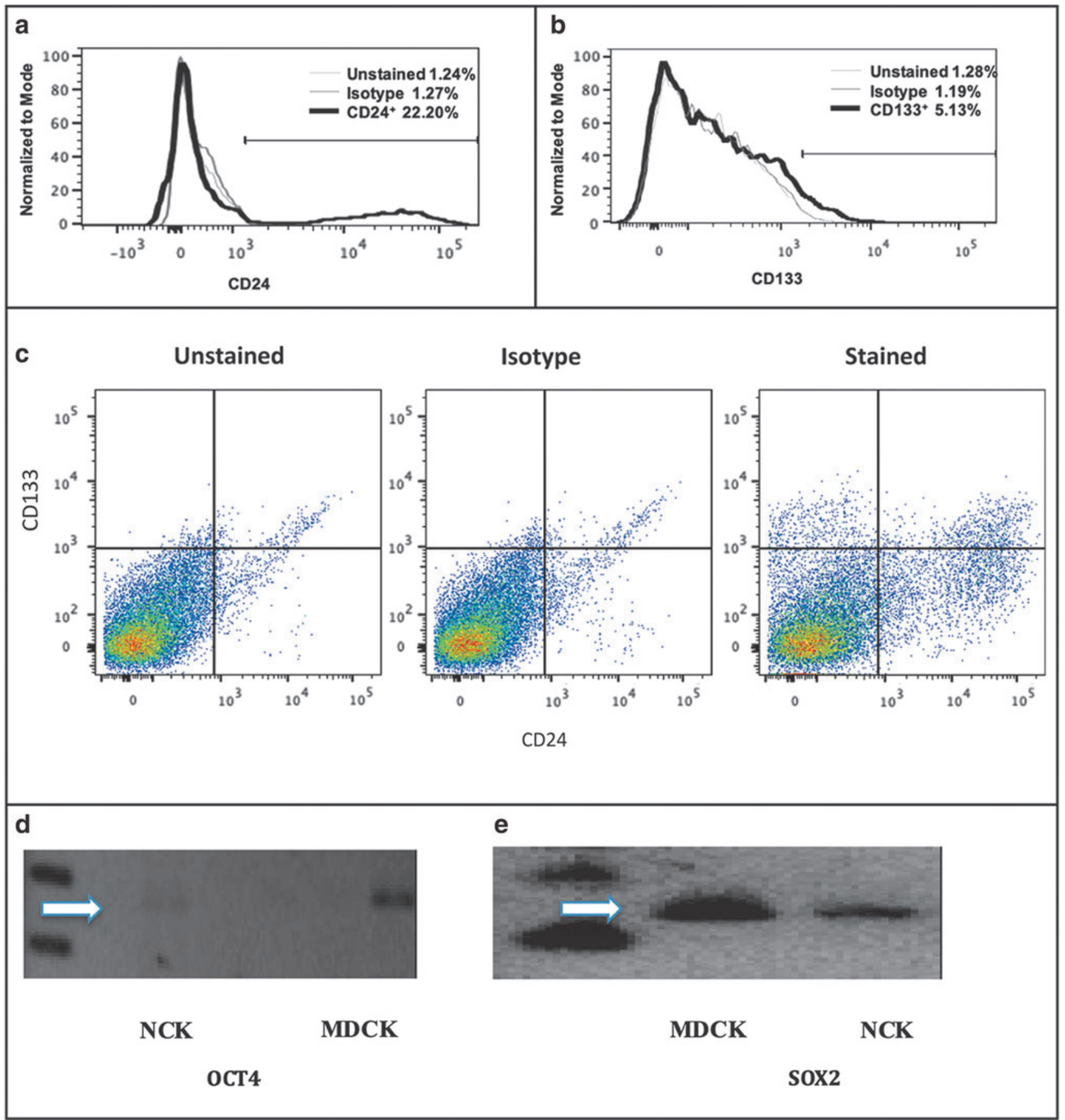

FIG. 2. Canine kidney epithelial cells express kidney stem cell markers. Flow cytometry analysis shows that canine kidney epithelial cells (clone DK-701) contain cell populations that express CD24 and CD133 on the surface. Histogram plots for CD24 (a), CD133 (b), and two-dimensional plots (c) are shown. Reverse transcription polymerase chain reaction revealed the expression of mRNA encoding OCT4 (d) (274 bp product shown by arrow head) and SOX-2 (e) (142 bp product shown by arrowhead) in both NCK cells and MDCK cells. MDCK, Madin-Darby canine kidney; NCK, normal canine kidney; OCT4, octamer-binding transcription factor 4; SOX2, SRY (sex determining region Y)-box 2.

human and canine adipose-derived mesenchymal stem cells $[6,7]$. Applying these protocols, we found that canine kidney epithelial cells were capable of osteogenic, adipogenic, and chondrogenic differentiations as revealed by positive Alizarin red (Fig. 4b), Oil red O (Fig. 4d), and Alcian blue staining (Fig. 4f), respectively, as compared with the control treatment shown in Figs. 4a, c, and e.

\section{Canine dome-forming kidney cells form ductal tubule-like organoids on Matrigel}

After canine kidney epithelial cells were plated on Matrigel as described in the Materials and Methods section, tubule-like structures formed in 10-14 days and ductal tubule-like organoids emerged 4-6 weeks later. Tubule-like 

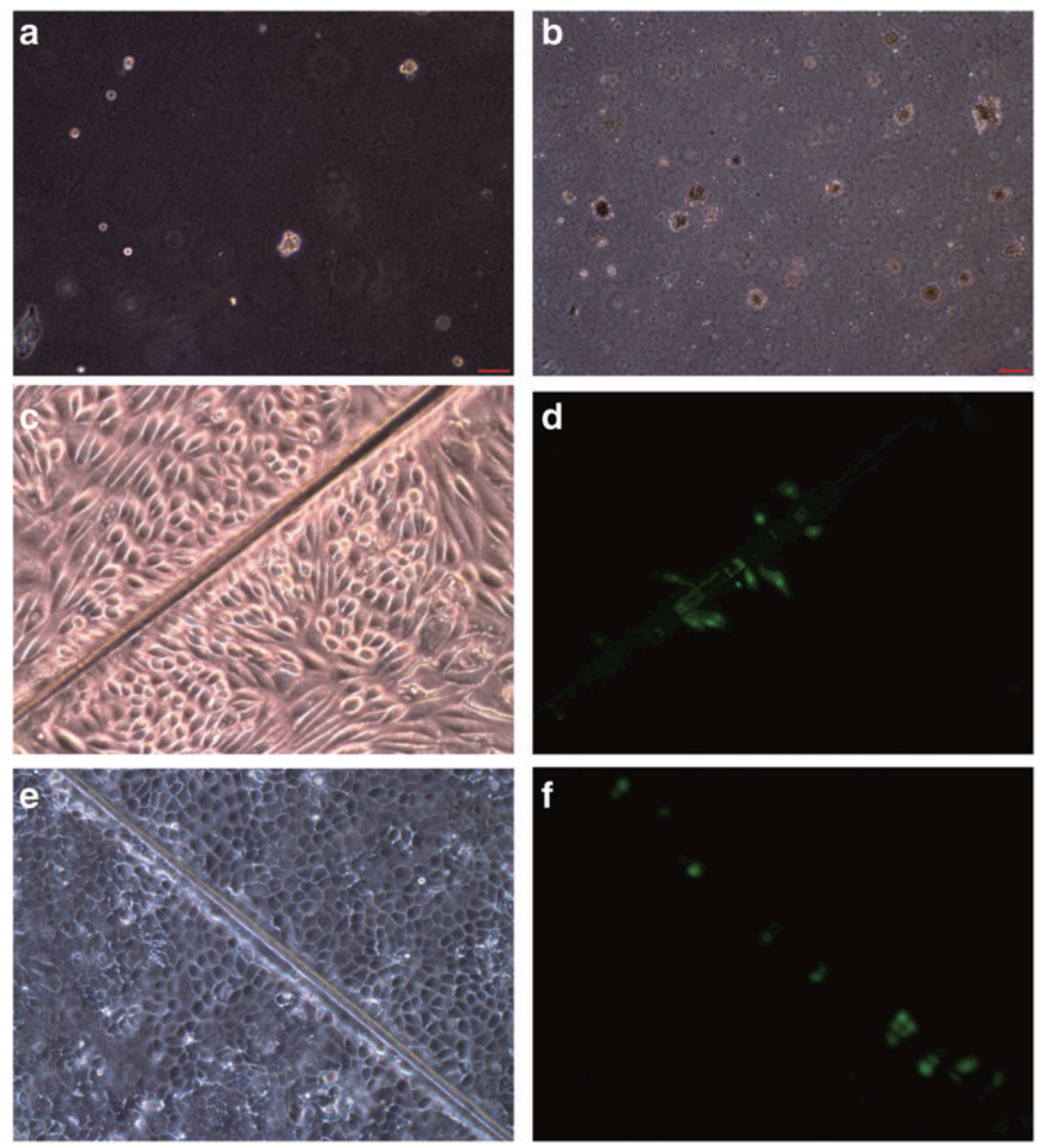

FIG. 3. Canine kidney epithelial cells exhibit several features of stem cells. The AIG frequency of dome-forming canine kidney epithelial cell cultures on Matrigel (a) was comparable with MDCK cell culture (b) $(\sim 4 \%$ in canine kidney epithelial cells vs. $\sim 8 \%$ in MDCK cells). In addition, normal canine epithelial cells (c, d) and MDCK cells $(\mathbf{e}, \mathbf{f})$ were deficient in GJIC. Scrape-loading dye transfer technique revealed that, in both cell types, the dyes were retained in damaged cells without any transfer to neighboring cells. Scale bars: (a) $100 \mu \mathrm{m}$; (b) $200 \mu \mathrm{m}$. AIG, anchorage-independent growth; GJIC, gap junctional intercellular communication. structure and tubular budding from ductal tubule organoids formed by NCK epithelial cells are shown in Fig. 5a and b, respectively. Figure $5 \mathrm{c}$ and $\mathrm{d}$ shows the ductal tubule-like organoids formed by NCK epithelial cells on Matrigel.

\section{Regulation of self-renewal and dome-forming tubular differentiation of canine stem/progenitor cells is STAT3 dependent}

The transcription factor STAT3 is required for the maintenance and self-renewal of ES cells [24]. In canine MDCK cells, cell confluence has been reported to activate STAT3 and trigger epithelial dome formation [13]. Therefore, we tested the effect of AG490, a STAT3 phosphorylation inhibitor, or LPS, an activator of STAT3, on self-renewal and dome formation. Experiments to determine the effect of STAT3 phosphorylation inhibitor AG490 on colonyforming efficiency were carried out. As shown in Fig. 6a, AG490 inhibited the formation of colonies in a dosedependent manner. An average of 99, 81, 71, and 22 colonies per plate were found for DMSO vehicle control and treatments with $2.5,5$, or $10 \mu \mathrm{M}$ AG490, respectively (the respective $P$ values were $0.0942,0.0251$, and 0.0005 ). AG490 treatment significantly affected dome formation only at concentrations $>5 \mu \mathrm{M}$. In contrast, treatment of these cells with
LPS, which activates STAT3, increased colony-forming frequencies in a dose-dependent manner (an average of 13, 15,23 , and 26 colonies per plate were found for the control and treatments with $0.1,0.2$, or $0.4 \mu \mathrm{g} / \mathrm{mL}$ LPS, respectively (the respective $P$ values were $0.5542,0.0201$, and 0.0079) (Fig. 6b).

\section{Discussion}

Dome formation can occur in cultured tubular epithelial cells originating from various tissues including the mammary gland [25] and the kidney [11]. This study demonstrates that dome-forming cells can be isolated from adult canine kidney tissues. Other than the well-known immortal canine kidney epithelial MDCK cell line, the isolation of dome-forming normal canine epithelial cells has not been reported. Furthermore, we show that these cells possess several characteristics of stem cells, that is, (1) high selfrenewal potential; (2) the ability to differentiate into multiple cell lineages; (3) expression of the stem cell markers OCT4 and SOX-2; (4) expression of cell surface markers CD24 and CD133; and (5) deficiency in GJIC.

In continuous subculture, these normal kidney epithelial cells were able to undergo $\sim 30$ population doublings. In confluent cultures in 12-well plates, floating cells that 
FIG. 4. Canine kidney epithelial cells can differentiate into mesenchymal lineages. NCK epithelial cells underwent osteogenic, adipogenic, and chondrogenic differentiation after treatment with respective induction cocktails (a-f). Cells treated with osteogenic induction cocktail were stained positive with Alizarin red (b), those treated with adipogenic induction cocktail were stained positive with Oil red $\mathrm{O}(\mathbf{d})$, whereas those treated with chondrogenic induction cocktail were stained positive with Alcian blue stain (f). Uninduced control cells (a, c, e) remained unstained after staining with the corresponding dye. Scale bars: $50 \mu \mathrm{m}$.
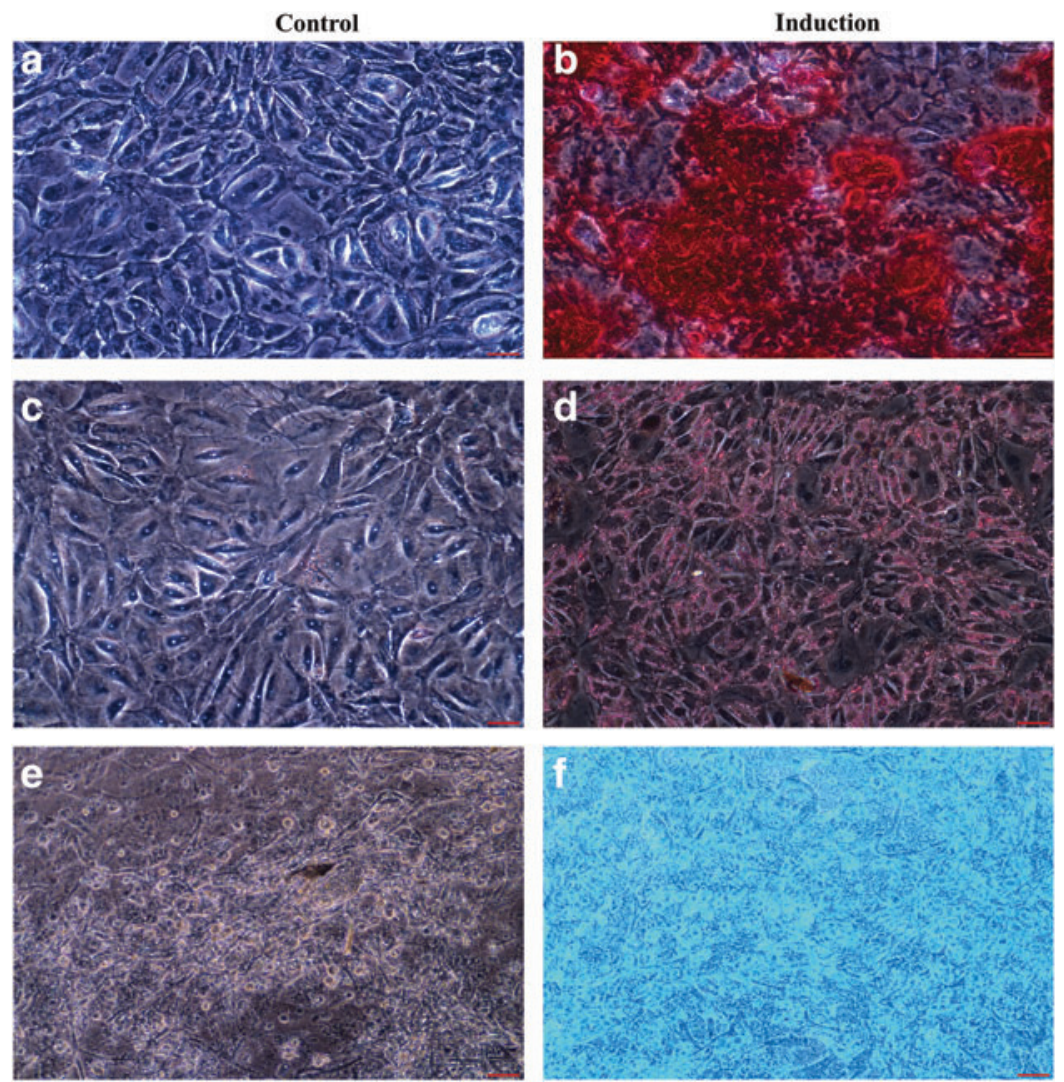

detached from the cell monolayer could be continuously collected and transferred into new plates to establish new cultures for $>13$ months. These new cell cultures maintained their dome-forming abilities. This appears to be a novel method for the long-term growth of stem cells that are sensitive to terminal differentiation after trypsinization. These NCK epithelial cells were capable of multilineage differentiation into adipocytes, osteoclasts, and chondrocytes, as well as tubular structure-like organoids on Matrigel. Whether these cells can also differentiate into other cell types remains to be examined.

The canine kidney epithelial stem cells derived in this study express OCT4 and SOX-2, but not NANOG. This does not cast doubt on their qualification as stem cells, since

FIG. 5. Canine kidney epithelial cells form ductal tubule-like structures. Ductal tubule-like organoids formed by NCK epithelial cells on Matrigel are shown (a-d). Tubulelike structures were formed after 10-14 days (a). The circle highlights tubular budding in ductal tubule organoids (b). Ductal tubulelike organoids emerged 4-6 weeks later (c, d). Scale bars: (a) $200 \mu \mathrm{m}$; (b) $100 \mu \mathrm{m}$; (c) $200 \mu \mathrm{m}$; (d) $50 \mu \mathrm{um}$.
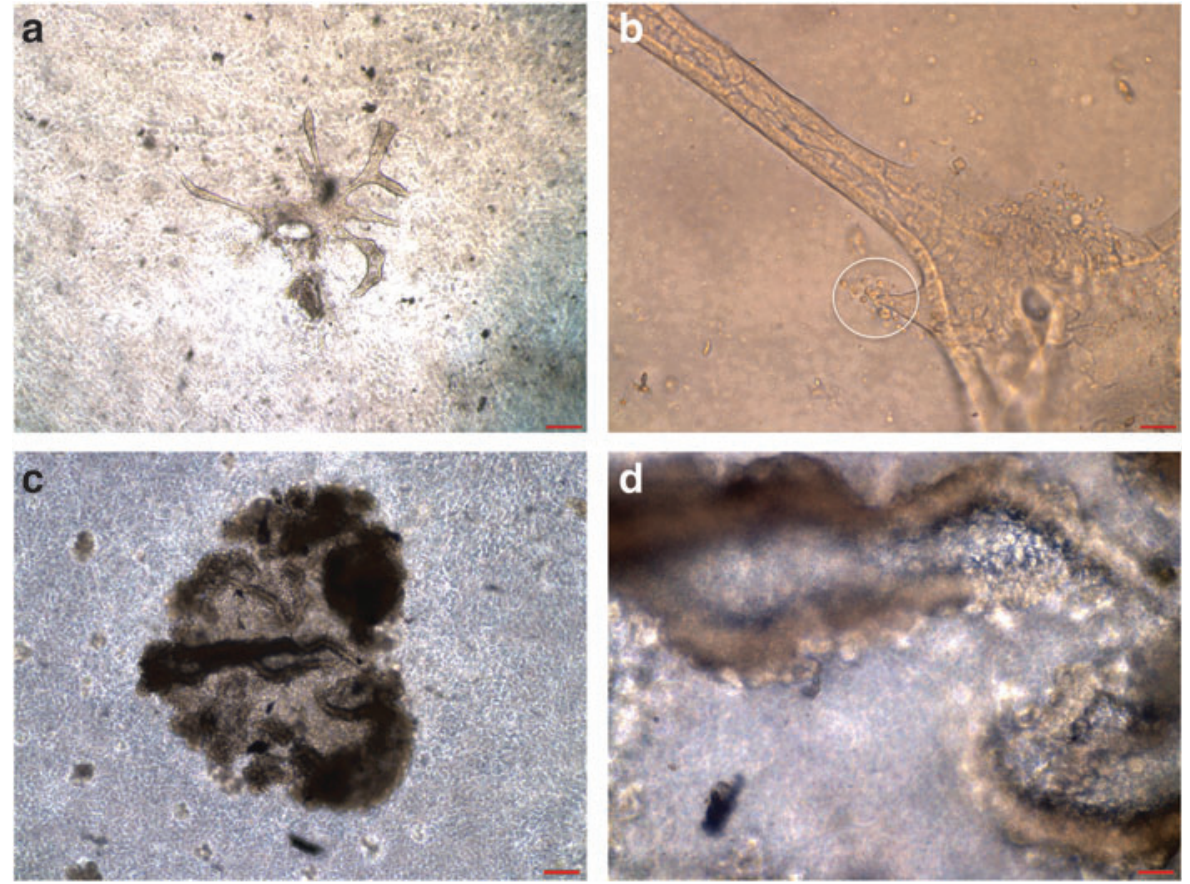
a Effect of AG490 on foci formation

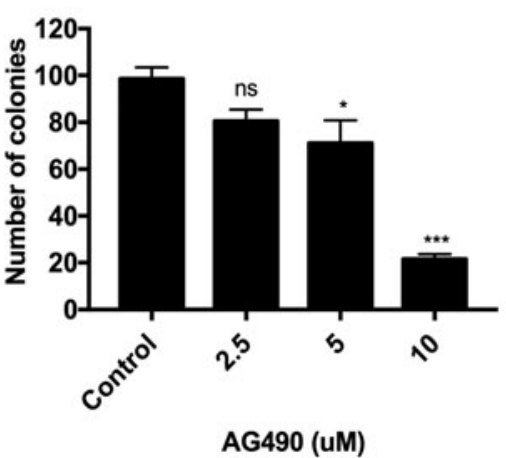

b Effect of LPS on foci formation

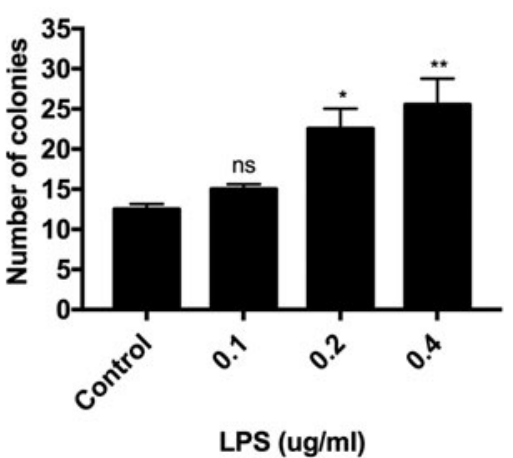

FIG. 6. STAT3 modulators can alter the ability of NCK epithelial cells to form colonies. The STAT3 phosphorylation inhibitor AG490 inhibited colony formation by NCK epithelial cells in a dose-dependent manner (a). Asterisks indicate statistically significant difference between each dose of AG490 treatment and vehicle control $(* * * P<0.001 ; * P<0.05$; ns, nonsignificant, $P=0.0942$ ). In contrast, LPS, an activator of STAT3, increased colony formation by NCK epithelial cells in a dose-dependent manner (b). Asterisks indicate statistically significant difference between each dose of LPS treatment and vehicle control $(* * P<0.01 ; * P<0.05$; ns, nonsignificant, $P=0.5542)$. LPS, lipopolysaccharide; STAT3, signal transducer and activator of transcription 3 .

the reprogramming of human renal proximal tubular cells into iPSCs required only OCT4 and SOX-2 [26]. Compared with the immortal canine MDCK cell line, NCK cells expressed lower levels of OCT4 and SOX-2. This is likely due to the lower frequency of stem cells in the population as indicated by their lower colony-forming efficiency $(0.18 \%)$. We found that $\sim 22 \%$ cells in the canine kidney epithelial cell population expressed CD24, 5\% cells expressed CD133, and $\sim 2.7 \%$ cells expressed both CD24 and CD133. It was previously shown that CD24 was found to be highly expressed by renal progenitor cells [27]. Similarly, CD133 ${ }^{+}$ kidney cells expressed several stem cell markers and integrated into developing tubules [28]. In fact, kidney cells expressing both CD24 and CD133 exhibited stem cell features such as self-renewal, multilineage differentiation, and expression of stem cell transcription factors including OCT4 [29-33]. The lower percentage of cells expressing both CD24 and CD133 compared with cells expressing only CD24 or CD133 found in this study may indicate that $\mathrm{CD} 24^{+} / \mathrm{CD} 133^{+}$cells are indeed the original stem cells that could undergo self-renewal or give rise to cells expressing only one of these two markers. This can be tested in a future study.

The canine kidney epithelial cells developed in this study share many stem/progenitor cell characteristics with the well-known immortal MDCK canine kidney cell line, that is, dome formation, deficiency in GJIC, expression of OCT4 and SOX-2, and the ability of AIG. The frequency of AIG of the cells described here was $\sim 4 \%$, which is higher than the colony-forming efficiency from single cells on plastic surfaces $(0.18 \%)$, but lower than the frequency of AIG $(\sim 8 \%)$ for the MDCK cell line.

The mentioned lines of evidence strongly suggest that both the adult canine kidney epithelial cells developed here, and the MDCK cell line, are canine kidney stem/progenitor cells. MDCK cells at confluency were found to activate STAT3 transcription and to trigger dome formation [13]. For our NCK epithelial cells, we observed that sustained cell growth required a high cell density $\left(>4,000 / \mathrm{cm}^{2}\right)$ and that dome formation was found in high cell density areas. We, therefore, suspect that, in both cell types, high cell density induces STAT3 expression, which promotes both stem cell self-renewal and differentiation into tubular cells. In agreement with the mentioned hypothesis, the STAT3 inhibitor AG490 was found to reduce colony-forming efficiency (Fig. 6a), whereas the STAT3 activator LPS was found to increase colony-forming efficiency (Fig. 6b). Putative adult stem cells were found at multiple locations in the kidney (proximal tubule, renal papilla, interstitium, Bowman's capsule, and glomerular parietal epithelium) of mice, rats, and humans [34,35]. Various methods have been used to isolate these putative renal stem cells, including retention of dyes, side populations, specific markers, and cell culture methods [35]. These renal/progenitor stem cells may have therapeutic potential [36] as exemplified by the three-dimensional reconstruction of kidney structures in vitro [37] and the repair of renal damage in mice with severe combined immunodeficiency [30].

Human kidney stem/progenitor cells can be developed from embryonic kidneys [30], tubular renal cells after iPSC reprogramming with OCT4 and SOX-2 [26], and fetal [38] or adult [29,39-46] kidneys. The isolation of kidney stem/ progenitor cells from embryonic and adult tissues relies primarily on the expression of cell surface markers, that is, CD133/CD24 [30,39-46]. After isolation, the potential therapeutic use of these cells depends on identifying proper media for long-term growth of a large number of cells. Human fetal kidney stem cells were found to be contact insensitive (ie, colonies formed on a layer of human fibroblasts that had been lethally irradiated with X-rays), GJIC deficient [38], and positive for OCT4 expression [46]. To our knowledge, ours is the first study to demonstrate that kidney stem/progenitor cells can give rise to dome-forming tubular cells. We believe that our cell culture method will be useful in the development of human stem cells from adult kidneys. This method is straightforward and requires relatively little tissue to develop sufficient quantities of stem cells for potential therapeutic applications. 


\section{Conclusion}

We have isolated and characterized the adult canine kidney epithelial cells with stem cell characteristics that can give rise to dome-forming tubular cells. Our results are consistent with the hypothesis that high cell density induces STAT3 expression, which promotes both stem cell selfrenewal and differentiation into tubular cells. Our cell culture method should be useful for the development of normal human kidney stem cells for clinical applications and for studying mechanisms of nephrotoxicity.

\section{Author Disclosure Statement}

No competing financial interests exist.

\section{Funding Information}

T.C. and S.J. were supported by Kaohsiung Chang Gung Memorial Hospital CMRPG8G1201. Research materials were supplied by Dr. C.-C. Chang's laboratory. M.N. was supported by the Comparative Medicine and Integrative Biology graduate program, and the Post DVM fellowship from Michigan State University.

\section{References}

1. United States Renal Data System. (2018). 2018 USRDS Annual Data report: Epidemiology of Kidney Disease in the United States. National Institutes of Health, National Institute of Diabetes and Digestive and Kidney Diseases, Bethesda, MD.

2. Zoccali C, K Anneke and KJ Jager. (2010). Chronic kidney disease and end-stage renal disease - a review produced to contribute to the report "the status of health in the European union: towards a healthier Europe." NDT Plus 3:213-224.

3. Hochedlinger K, YYamada, C Beard and R Jaenisch. (2005). Ectopic expression of Oct-4 blocks progenitor cell differentiation and causes dysplasia in epithelial tissues. Cell 121:465-477.

4. Kao CY, K Nomata, CS Oakley, CW Welsch and CC Chang. (1995). Two types of normal human breast epithelial cells derived from reduction mammoplasty: phenotypic characterization and response to SV40 transfection. Carcinogenesis 16:531-538.

5. Sun W, KS Kang, I Morita, JE Trosko and CC Chang. (1999). High susceptibility of a human breast epithelial cell type with stem cell characteristics to telomerase activation and immortalization. Cancer Res 59:6118-6123.

6. Lin TM, JL Tsai, SD Lin, CS Lai and CC Chang. (2005). Accelerated growth and prolonged lifespan of adipose tissue-derived human mesenchymal stem cells in a medium using reduced calcium and antioxidants. Stem Cell Dev 14: 92-102.

7. Neupane M, CC Chang, M Kiupel and V YuzbasiyanGurkan. (2008). Optimization of growth and differentiation of canine adipose-derived mesenchymal stem cells. Tissue Eng 14:1007-1015.

8. Yang YC, SW Wang, HY Hung, CC Chang, IC Wu, YL Huang, TM Lin, JL Tsai, A Chen, et al. (2007). Isolation and characterization of human gastric cell lines with stem cell phenotypes. J Gastroenterol Hepatol 22:1460-1468.

9. Kim S, N Kiyosawa, LD Burgoon, CC Chang and TR Zacharewski. (2013). PPAR $\alpha$-mediated responses in human adult liver stem cells: in vivo/in vitro and cross-species comparisons. J Steroid Biochem Mol Biol 138:236-247.

10. Wang KH, AP Kao, CC Chang, TC Lin and TC Kuo. (2015). Upregulation of Nanog and Sox-2 genes following ectopic expression of Oct-4 in amniotic fluid mesenchymal stem cells. Biotechnol Appl Biochem 62:591-597.

11. Lever JE. (1981). Regulation of dome formation in kidney epithelial cell cultures. Ann N Y Acad Sci 372:371-383.

12. Hansson GC, K Simons and G van Meer. (1986). Two strains of the Madin-Darby canine kidney (MDCK) cell line have distinct glycosphingolipid compositions. EMBO J 5:483-489.

13. Su HW, HH Yeh, SW Wang, MR Shen, TL Chen, PR Kiela, FK Ghishan and MJ Tang. (2007). Cell confluenceinduced activation of signal transducer and activator of transcription-3 (Stat3) triggers epithelial dome formation via augmentation of sodium hydrogen exchanger-3 (NHE3) expression. J Biol Chem 282:9883-9894.

14. Smith J, E Ladi, MP Margot and M Noble. (2000). Redox state is a central modulator of the balance between selfrenewal and differentiation in dividing glial precursor cells. Proc Natl Acad Sci U S A 97:10032-10037.

15. De Flora S, A Izzotti, F D'Agostini and RM Balansky. (2001). Mechanisms of N-acetylcysteine in the prevention of DNA damage and cancer, with special reference to smoking-related end-points. Carcinogenesis 22:999-1013.

16. Hata RI and H Senoo. (1989). L-ascorbic and 2-phosphate stimulates collagen accumulation, cell proliferation, and formation of a three-dimensional tissue-like substance by skin fibroblasts. J Cell Physiol 138:8-16.

17. Chepda T, M Cadau, P Girin, J Frey and A Chamson. (2001) Monitoring of ascorbate at a constant rate in cell culture: effect on cell growth. In Vitro Cell Dev Biol Anim 37:26-30.

18. Buettner GR. (1988). In the absence of catalytic metals ascorbate does not autoxidize at $\mathrm{pH} 7$ : ascorbate as a test for catalytic metals. J Biochem Biophys Methods 16:27-40.

19. Galli M, F van Gool, A Rongvaux, A Fabienne and L Oberdan. (2010). The nicotinamide phosphoribosyltransferase: a molecular link between metabolism, inflammation, and cancer. Cancer Res 70:8-11.

20. Van der Veer E, C Ho, C O'Neil, N Barbosa, R Scott, SP Cregan and JG Pickering. (2007). Extension of human cell lifespan by nicotinamide phosphoribosyltransferase. J Biol Chem 282:10841-10845.

21. Chang CC, JA Boezi, ST Warren, CL Sabourin, PK Liu, L Glatzer and JE Trosko. (1982). Isolation and characterization of a UV-sensitive hypermutable aphidicolin-resistant Chinese hamster cell line. Somatic Cell Genet 7:235-253.

22. El-Fouly MH, JE Trosko and CC Chang. (1987). Scrapeloading and dye transfer: a rapid and simple technique to study gap junctional intercellular communication. Exp Cell Res 168:422-430.

23. Chang CC. (2006). Recent translational research: stem cells as the root of breast cancer. Breast Cancer Res 8:103.

24. Niwa H, T Burdon, I Chambers and A Smith. (1998). Selfrenewal of pluripotent embryonic stem cells is mediated via activation of STAT3. Genes Dev 12:2048-2060.

25. Zucchi I, L Bini, D Albani, R Valaperta, S Liberatori, R Raggiaschi, C Montagna, L Susani and O Barbieri. (2002). Dome formation in cell cultures as expression of an early stage of lactogenic differentiation of the mammary gland. Proc Natl Acad Sci U S A 99:8660-8665.

26. Montserrat N, MJ Ramírez-Bajo, Y Xia, I SanchoMartinez, D Moya-Rull, L Miquel-Serra, S Yang, E Nivet, 
C Cortina, et al. (2012). Generation of induced pluripotent stem cells from human renal proximal tubular cells with only two transcription factors, Oct4 and Sox 2 . J Biol Chem 287:24131-24138.

27. Challen GA, G Martinez, MJ Davis, DF Taylor, M Crowe, RD Teasdale, SM Grimmond and MH Little. (2004). Identifying the molecular phenotype of renal progenitor cells. J Am Soc Nephrol 15:2344-2357.

28. Ward HH, E Romero, A Welford, G Pickett, R Bacallao, VH Gattone 2nd, SA Ness, A Wandinger-Ness and T Roitbak. (2011). Adult human CD133/1(+) kidney cells isolated from papilla integrate into developing kidney tubules. Biochim Biophys Acta 1812:1344-1357.

29. Sagrinati C, GS Netti, B Mazzinghi, E Lazzeri, F Liotta, F Frosali, E Ronconi, C Meini, M Gacci, et al. (2006). Isolation and characterization of multipotent progenitor cells from the Bowman's capsule of adult human kidneys. J Am Soc Nephrol 17:2443-2456.

30. Lazzeri E, C Crescioli, E Ronconi, B Mazzinghi, C Sagrinati, GS Netti, ML Angelotti, E Parente, L Ballerini, et al. (2007). Regenerative potential of embryonic renal multipotent progenitors in acute renal failure. J Am Soc Nephrol 18:3128-3138.

31. Rosenberg ME and S Gupta. (2007). Stem cells and the kidney: where do we go from here? J Am Soc Nephrol 18: 3018-3020.

32. Shrestha S, S Somji, DA Sens, A Slusser-Nore, DH Patel, E Savage and SH Garrett. (2017). Human renal tubular cells contain CD24/CD133 progenitor cell populations: implications for tubular regeneration after toxicant induced damage using cadmium as a model. Toxicol Appl Pharmacol 331:116-129.

33. Ehsani E, S Shekarchian, H Baharvand, N Aghdami and R Moghadasali. (2019). Improved differentiation of human enriched $\mathrm{CD} 133^{+} \mathrm{CD} 24^{+}$renal progenitor cells derived from embryonic stem cell with embryonic mouse kidneyderived mesenchymal stem cells co-culture. Differentiation 109:1-8.

34. Hishikawa K, O Takase, M Yoshikawa, T Tsujimura, M Nangaku and T Takato. (2015). Adult stem-like cells in kidney. World J Stem Cells 7:490-494.

35. Gupta S and ME Rosenberg. (2008). Do stem cells exist in the adult kidney? Am J Nephrol 28:607-613.

36. Bussolati B and G Camussi. (2015). Therapeutic use of human renal progenitor cells for kidney regeneration. Nat Rev Nephrol 11:695-706.

37. Kitamura S, H Sakurai and H Makino. (2015). Single adult kidney stem/progenitor cells reconstitute three-dimensional nephron structures in vitro. Stem Cells 33:774-784.
38. Chang CC, JE Trosko, MH El-Fouly, RE GibsonD'Ambrosio and SM D'Ambrosio. (1987). Contact insensitivity of a subpopulation of normal human fetal kidney epithelial cells and of human carcinoma cell lines. Cancer Res 47:1634-1645.

39. Oliver JA, O Maarouf, FH Cheema, TP Martens and Q AlAwqati. (2004). The renal papilla is a niche for adult kidney stem cells. J Clin Invest 114:795-804.

40. Bussolati B, S Bruno, C Grange, S Buttiglieri, MC Deregibus, D Cantino and $\mathrm{G}$ Camussi. (2005). Isolation of renal progenitor cells from adult human kidney. Am J Pathol 166:545-555.

41. Gupta S, C Verfaillie, D Chmielewski, S Kren, K Eidman, J Connaire, Y Heremans, T Lund, M Blackstad, et al. (2006). Isolation and characterization of kidney-derived stem cells. J Am Soc Nephrol 17:3028-3040.

42. Ronconi E, C Sagrinati, ML Angelotti, E Lazzeri, B Mazzinghi, L Ballerini, E Parente, F Becherucci, M Gacci, et al. (2009.) Regeneration of glomerular podocytes by human renal progenitors. J Am Soc Nephrol 20:322-332.

43. Park HC, K Yasuda, MC Kuo, J Ni, B Ratliff, P Chander and MS Goligorsky. (2010). Renal capsule as a stem cell niche. Am J Physiol Renal Physiol. 298:F1254-F1262.

44. Lindgren D, AK Boström, K Nilsson, J Hansson, J Sjölund, C Mölle, K Jirström, E Nilsson, G Landberg, H Axelson and ME Johansson. (2011). Isolation and characterization of progenitor-like cells from human renal proximal tubules. Am J Pathol 178:828-837.

45. Romagnani P and G Remuzzi. (2014). CD133 ${ }^{+}$renal stem cells always co-express CD24 in adult human kidney tissue. Stem Cell Res 12:828-829.

46. Tai MH, CC Chang, LK Olson and JE Trosko. (2005). Oct4 expression in adult human stem cells: evidence in support of the stem cell theory of carcinogenesis. Carcinogenesis 26:495-502.

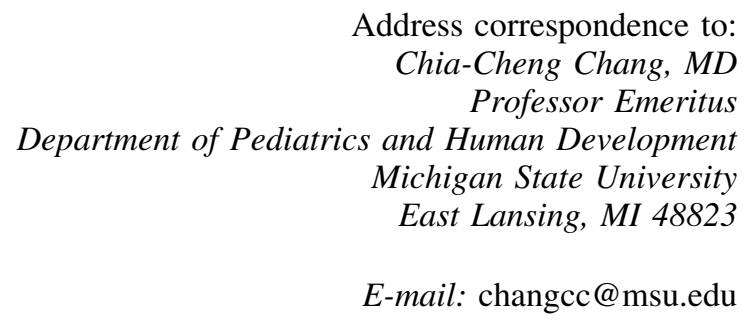

Received for publication March 22, 2019

Accepted after revision September 5, 2019

Prepublished on Liebert Instant Online September 7, 2019 